\title{
ESCENARIOS DE LA CONFLICTIVIDAD: MOTINES Y DESÓRDENES PÚBLICOS EN LA NAVARRA DEL ANTIGUO RÉGIMEN ${ }^{1}$
}

\author{
Javier RUIZ ASTIZ \\ Universidad de Navarra
}

\begin{abstract}
RESUMEN: Durante el Antiguo Régimen los comportamientos violentos impregnaron cualquier esfera de la vida pública. Es por ello por lo que desórdenes públicos y altercados se originaron en multitud de espacios en cada comunidad. El presente artículo surge con el objetivo primordial de tratar de analizar esta realidad para el caso del reino de Navarra entre 1512 y 1808 . A través de este estudio se podrá comprobar los distintos emplazamientos que se han encontrado. Gracias a ello, podremos constatar si existió cierta lógica con los disturbios que estallaron en cada uno de estos lugares.
\end{abstract}

PALABRAS CLAVE: Desórdenes públicos; Violencia colectiva; Emplazamiento; Reino de Navarra; Edad Moderna.

ABSTRACT: During the Old Regime the violent behaviors impregnated any sphere of the public life. It is for that reason why public disorders and argument were originated in multitude of spaces in each community. Present article arises with the fundamental objective to try to analyze this reality for the case of the Kingdom of Navarre between 1512 and 1808. Through this study will be able to be verified the different locations that have been. Thanks to it, we will be able to state if certain logic with the disturbances existed that exploded in each of these sites.

KEYWORDS: Public disorders; Collective violence; Location; Kingdom of Navarre; Early Modern Age.

\section{INTRODUCCIÓN}

El presente estudio surge motivado por la ausencia de investigaciones que se hayan dedicado a analizar el fenómeno de la violencia colectiva de un modo exhaustivo y detallado. Si bien hasta la fecha han primado los trabajos que hacían hincapié en la espontaneidad de muchos de los desórdenes públicos encontrados, sin embargo, considero que esta pauta no se muestra tan fiel para la mayoría de los casos encontrados en el reino de Navarra. En nuestro caso sostengo que por encima de todo primó la planificación de los altercados del orden público, pudiéndose hablar de la existencia de una detallada estrategia en numerosas ocasiones. A su

${ }^{1}$ Recibido el 1 de julio de 2011. Aceptado en el Consejo de 8 de noviembre de 2011. 
vez, estoy convencido de que detrás de estos comportamientos violentos, pese a lo que pueda pensarse, existió un profundo conocimiento de los límites que no podían rebasarse. De esta manera, salta a la vista que existió una conciencia comunitaria que provocó que muchos de estos sucesos se reprodujesen como una pauta repetitiva a lo largo de los siglos. Ese bagaje otorgaba a sus participantes una exquisita sabiduría sobre cuándo, cómo y hasta dónde podían ir en la búsqueda de sus objetivos finales.

En la obtención de esos patrones de comportamiento voy a prestar una especial atención a ciertas variables espaciales para llegar a comprender en qué lugares se ocasionaron los desórdenes públicos en la Navarra del Antiguo Régimen. No obstante, antes que nada resulta imprescindible señalar que este trabajo ha sido posible porque forma parte de las investigaciones que he desarrollado para la elaboración de la Tesis Doctoral, cuyo título es Desórdenes públicos y violencia colectiva en la Navarra moderna (1512-1808). De esta manera, gracias a la documentación procesal consultada tanto en el Archivo General de Navarra como en el Archivo Diocesano de Pamplona se ha logrado alcanzar una visión de conjunto sobre el entramado interno del que se dotaron aquellos desórdenes públicos. Pese a ello, estoy convencido de que no habría logrado alcanzar esta soltura si no hubiese consultado en ambos archivos un total de 336 procesos judiciales, de un total de 800 que han sido localizados en sus fondos. Por tanto, no cabe ningún género de duda sobre el enorme valor que atesoran las fuentes judiciales, ya que éstas se muestran como un medio de un extraordinario valor para poder adentrarnos en este complejo mundo como es el de la violencia colectiva y la conflictividad.

Resumiendo, creo que si hubo algún aspecto que caracterizó a este tipo de comportamientos violentos éste fue su distribución espacial, puesto que todos ellos se articularon en torno a un espacio concreto en donde se desarrollaron, compartiendo en la mayoría de los casos no sólo sus fines y objetivos, sino también sus formas y técnicas. Debido a ello el presente artículo tratará de analizar los distintos conflictos que se originaron en el reino de Navarra durante los siglos modernos para intentar comprobar si éstos afectaron prácticamente a todos los ámbitos de la vida comunitaria. Pudiéndose poner de manifiesto si los conflictos se reprodujeron en lugares establecidos no sólo para el ocio y la diversión, sino incluso en espacios propios para la devoción y el culto, así como en los destinados a la representación social y política.

\section{LOS ESPACIOS DE LA CONFLICTIVIDAD}

Los espacios concretos en los que se desarrollaron los sucesos que supusieron la 
alteración del orden público en la Navarra moderna van a destacar por su variedad. En total son seis los lugares que hemos creído encontrar, pese a que no se trata de un protagonismo equilibrado, puesto que siempre hay alguno que sobresale por encima del resto. Como ya he indicado, gracias a la consulta de 336 causas judiciales repartidas entre el Archivo General de Navarra y el Archivo Diocesano de Pamplona se ha logrado comprobar algunos de los aspectos que caracterizaron a los desórdenes públicos. Entre los datos que nos han aportado aparecen los enclaves en los que tuvieron lugar todos los disturbios que han sido estudiados para el presente artículo.

Tabla I. Distribución espacial de los desórdenes

\begin{tabular}{lc}
\hline \multicolumn{1}{c}{ Espacio } & Número de sucesos \\
\hline Calle & 175 \\
Plaza pública & 71 \\
Recinto religioso & 30 \\
Ayuntamiento & 27 \\
Campo-camino & 21 \\
Taberna $\quad 12$ \\
\hline \multicolumn{2}{c}{ Total } \\
\hline
\end{tabular}

De esta manera, el reparto espacial de la violencia colectiva en el reino de Navarra se estructura de la siguiente manera: 1/ calle: se trató del emplazamiento por excelencia en donde podrán encontrarse prácticamente la totalidad de las tipologías de desórdenes que se han localizado, da buena muestra de ello porque registra el mayor número de casos, apareciendo en 175 ocasiones, lo que supone que el 52\% de los sucesos vistos se desarrollaron en estas zonas; 2/ plazas públicas: junto a la calle jugó un papel importante en multitud de altercados, es por ello que se encuentra detrás de 71 casos, lo que representa un relevante $21 \%$ del total; $3 /$ recintos religiosos: los espacios sagrados (iglesias, parroquias, monasterios, conventos o cementerios) fueron un foco de conflictividad en determinadas ocasiones, pauta que se evidencia en 30 procesos judiciales, dejándonos constancia de su presencia en un 9\% de los desórdenes analizados; 4/ ayuntamientos y concejos: podrían ser denominados como lugares de representación política a escala local, ya que los 27 casos que nos testimonian hacen mención expresa a dichas situaciones, situándose su presencia en un 8\% de los sucesos examinados; 5/ zonas apartadas de las poblaciones: entre éstas vamos a poder apreciar tanto los campos de labor empleados por los agricultores y ganaderos, así como los caminos que facilitaban las comunicaciones con otras localidades, aunque su peso es bastante reducido al aparecer en 21 ocasiones, lo que representa un 6\% del total de los disturbios que han sido trabajados; 6/ tabernas: los espacios tabernarios debieron desempeñar un protagonismo mayor, caso de las pendencias y quimeras 
entre cuadrillas, pero únicamente se han podido registrar 12 sucesos cuyo foco de tensión surgió en estos emplazamientos, lo que supone un escaso $4 \%$.

Gráfico I. Distribución espacial de los desórdenes

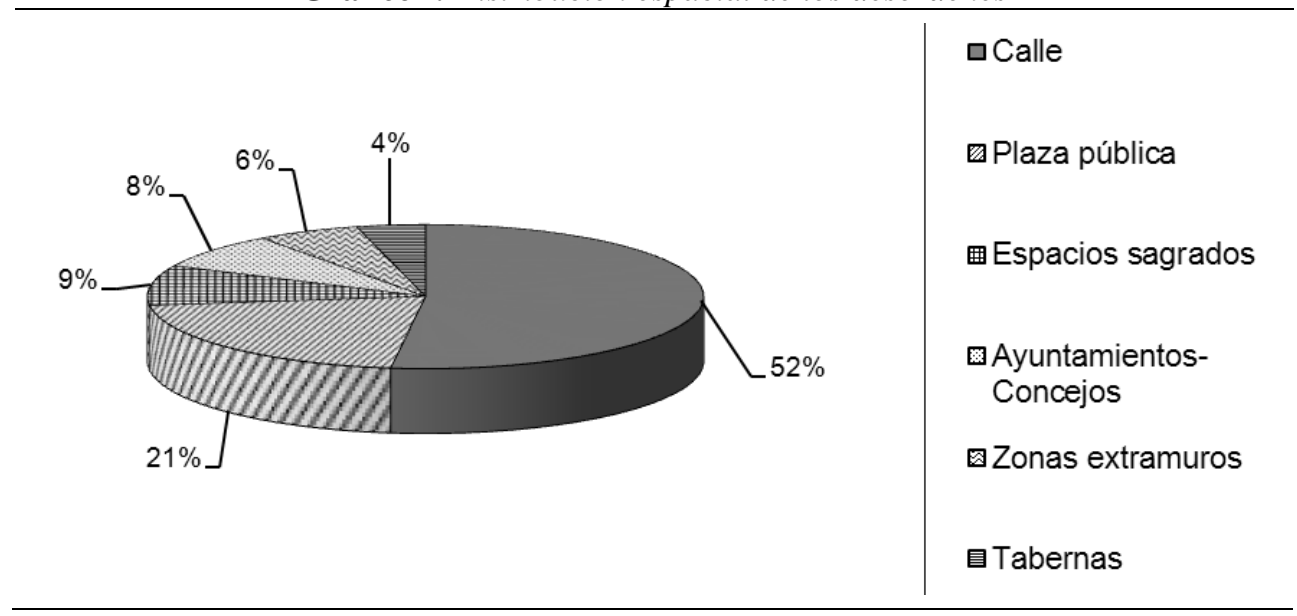

A continuación, una vez realizado este somero repaso a los espacios de la conflictividad en la Navarra moderna me centraré en el análisis pormenorizado de cada uno de ellos. Para ello considero conveniente mostrar los diferentes tipos de desórdenes que acontecieron en cada uno de éstos, tratando de comprender sus peculiaridades y especificidades para lograr trazar un completo panorama de los comportamientos violentos en relación con los lugares en donde aquellos se registraron.

\section{LA CALLE: TEATRO DEL CONFLICTO}

Ésta se erigió, sobre todo de noche, en un punto de encuentro que condujo con frecuencia a discusiones y conflictos de todo tipo ${ }^{2}$. La pujanza que manifiesta este enclave ha permitido localizar una representación de los distintos tipos de altercados que se originaron en Navarra entre 1512 y 1808 . Bien es cierto que no todos manifiestan el mismo grado de protagonismo. Tanto es así que, por encima

\footnotetext{
${ }^{2}$ Véanse a este respecto los trabajos de BERNAL SERNA, L. M. (2007). Sociedad y violencia en Portugalete (1550-1833). Portugalete: Gráficas Berriz, p. 44; ALMAZÁN, I. (1990). «El recurso a la fuerza. Formas de violencia en el Vallés occidental durante el siglo XVI». Historia Social, 6, p. 96; TAYLOR, S. (2008). Honor and Violence in Golden Age Spain. USA: Yale University Press, p. 144; RODRÍGUEZ SÁNCHEZ, A. (1995). «La historia de la violencia: Espacios y formas en los siglos XVI y XVII». En BARros, C. (ed.). Historia a debate. Actas del Congreso Internacional. Santiago de Compostela: Historia a debate, p. 119. Vol. II.
} 
del resto sobresalen las rondas nocturnas y la aparición de escritos injuriosos. El resto de sucesos que se han registrado (altercados fruto de las fiestas locales, cencerradas, rencillas vecinales y motines antiseñoriales) muestran una representatividad similar.

Tabla II. Desórdenes callejeros

\begin{tabular}{lc}
\hline \multicolumn{1}{c}{ Tipo de disturbio } & Número de sucesos \\
\hline Rondas nocturnas & 52 \\
Escritos injuriosos & 45 \\
Festividades locales & 25 \\
Cencerradas & 24 \\
Rencillas vecinales & 18 \\
Motines antiseñoriales & 11 \\
\hline \multicolumn{1}{c}{ Total } & 175 \\
\hline
\end{tabular}

Gráfico II. Altercados originados en la calle

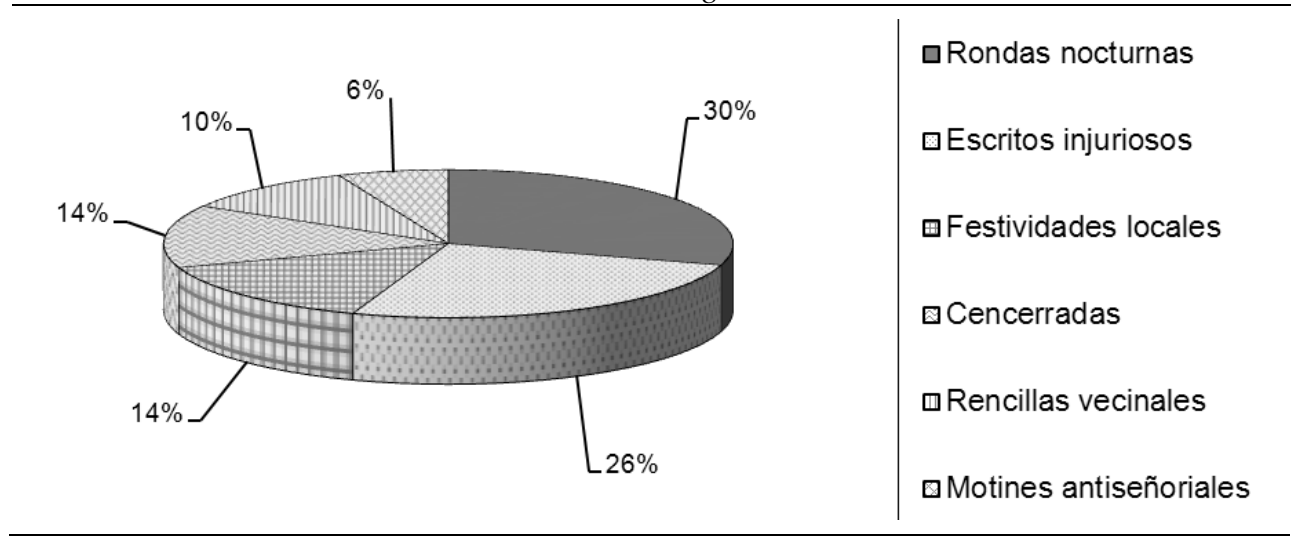

Dentro de los altercados que podemos encontrarnos merece la pena destacar, en primer lugar, las pendencias y quimeras en las que se vieron involucradas distintas cuadrillas mientras participaban en rondas nocturnas. Así sucedió, por ejemplo, en Artajona en 1592 puesto que allí la cuadrilla conformada por Andrés Martínez, Pedro de Echaide, Miguel de Lodosa y Pedro Lascarro "andando paseando por la calle pública" 3 tuvo un enfrentamiento con otros mozos, entre los que se encontraron Juan Miguel Sebastián Lascarro, Salvador Lascarro, Juan de Ororbia, Pedro de Berástegui y Domingo de Mendiondo. Comprobándose que para Navarra éste fue el escenario primordial, puesto que el 52\% de los procesos consultados así

${ }^{3}$ AGN, Tribunales Reales. Procesos, núm. 13269, fol. 3. 
nos lo ponen de manifiesto, aunque cabe indicar que esta pauta no fue única y exclusiva de nuestro territorio, ya que son abundantes las referencias que sobre el protagonismo de la calle pública existen por todo el continente europeo ${ }^{4}$.

A su vez, durante las aventuras nocturnas en las que los vocingleros se dedicaron a entonar jocosas serenatas lo cierto es que no encontraron mejor resonancia para sus hirientes estrofas que la que les brindó -como también indica Krausman $^{5}$ - la estrechez de algunas callejuelas. No debe sorprendernos que una noche de marzo de 1778 "algunos sujetos andaban por la calle de música", entre quienes se encontraron Francisco de Berastegui, Matías de Solorzano, Joaquín Alcalde y Bernardo Echeverría. Cabe destacar, como también lo hace Gil Massa ${ }^{7}$, la función de los cantones y callejones. Estos puntos fueron muy transitados, por lo que se convirtieron en lugares especialmente proclives dada su configuración para cometer actos violentos. Debido a ello una noche de 1596 en la localidad de Sangüesa "anduvieron por las calles y cantones" Pedro de Orbaiz, Guillén de Grez, Salvador Zurita, Juan de Ansó y Juan Remírez "voceando y gritando mudadas las voces difamando a gentes honradas" $"$. Como puede comprobarse los ritos propios de las cencerradas no encontraron mejor escaparate para poder publicitar sus denuncias que las calles públicas. Es por ello que pueden ser constatados diferentes ejemplos. Así en la ciudad de Estella el 25 de julio de 1729 fueron cantadas en la calle la Rúa diferentes chanzas y palabras descompuestas contra las hijas solteras de Antonio de Cartagena, Micaela y Manuela, "tratándolas con diferentes injurias a sus estados". Igual sucedió el 10 de noviembre de 1744 en la ciudad de Pamplona, en donde a cosa de las doce horas de la noche hubo una cencerrada protagonizada

${ }^{4}$ Muchembled, R. (1998). «Les théâtres du crime. Villes et campagnes face à la justice (XVIeXVIIIe siècle)». En D'Hollander, P. (ed.). Violences en Limousin à travers les siècles. Limoges : Pulim, p. 94; CrouZET-Pavan, E. (1984). «Violence, société et pouvoir à Venise (XIVe-XVe siècles): forme et évolution de rituels urbains». Mélanges de l'Ecole française de Rome. Moyen-Age. Temps modernes, 96-2, p. 910; MENDOZA GARRIDO, J. M. (1999). Delincuencia y represión en la Castilla bajomedieval. Granada: Grupo Editorial Universitario, p. 162, FARGE, A.; ZYSBERG, A. (1979). «Les théâtres de la violence a Paris au XVIIIe siècle». Annales. Histoire, Sciences Sociales, 34-5, p. 1005; BAZÁN DíAZ, I. (1995). Delincuencia y criminalidad en el País Vasco en la transición de la Edad Media a la Moderna. Vitoria-Gasteiz: Gobierno Vasco, p. 232; ChiffoleAU, J. (1980). «La violence au quotidien. Avignon au XIVe siècle d'après les registres de la cour temporelle». Mélanges de l'École Française de Rome, 92, p. 351.

${ }^{5}$ Krausman Ben-Amos, I. (1994). Adolescence and Youth in Early Modern England. USA: Yale University Press, p. 194.

${ }^{6}$ AGN, Tribunales Reales. Procesos, núm. 34147, fol. 6.

${ }^{7}$ Gil Massa, J. A. (2003). «Espacios Públicos en Bergara». Vasconia, 33, p. 433.

${ }^{8}$ AGN, Tribunales Reales. Procesos, núm. 99628, fol. 8.

${ }^{9}$ AGN, Tribunales Reales. Procesos, núm. 205738, fol. 4. 
por Nicolás Salinas, Lucas de Oronoz, José de Sada, Agustín de Lazcano y Francisco Chaparro, presbíteros, contra las hijas de Tomás de Sarasa. Éstos "con mucha gritería y tañendo una guitarra" $" 10$ en la calle Mayor hicieron burla y mofa de Micaela, y al mismo tiempo cantaron contra su hermana Lorenza.

Junto a las prácticas chariváricas otro de los desórdenes públicos que se desarrollaron por las calles fueron los propios de las jornadas carnavalescas. En aquellas ocasiones la gente aprovechaba el anonimato de los disfraces y las máscaras para dedicarse a amedrentar a los vecinos no sólo entonando jocosas coplillas y burdas injurias, sino también lanzando piedras o bolas de nieve contra puertas y ventanas. Así sucedió, por ejemplo, durante el mes de febrero de 1560 en la ciudad de Pamplona, en donde tras tocar las campanas al toque de queda salieron distintas personas acompañadas de armas, máscaras e instrumentos musicales haciendo algaradas. Según Gracián de Gárate fueron vistos "siete u ocho mancebos que iban por la calle de San Francisco con un hacha encendida y todos llevaban máscaras"11. Lo mismo sucedió en Cascante el 17 de febrero de 1599, pues durante los carnavales celebrados en dicha localidad fueron injuriados muchos vecinos. En la demanda interpuesta por el Fiscal resultaron acusados Jerónimo Calvillo, Miguel Esteban Ruiz, Pedro Martín, Marco de Urriza, Pedro Calvillo y Juan Ruiz porque "anduvieron por las calles alborotando el lugar y diciendo muchas palabras feas e injuriosas e infamatorias contra muchas personas honradas" $"$.

Por otro lado, tampoco debemos olvidarnos que las fiestas locales fueron no sólo un momento propicio para que surgiesen pendencias y riñas armadas con determinados grupos, sino que también sirvieron para denunciar públicamente a sus opositores en forma de cantares y pullas. De este modo, el 8 de julio de 1718 en Pamplona "anduvieron diferentes personas en danzas y bailes con juglares, guitarras y otros instrumentos por diferentes calles con mucho desorden causando nota y escándalo y dando motivos de inquietud a sus vecinos" ${ }^{\prime 13}$. Aquella noche los vecinos y parroquianos de San Lorenzo estuvieron festejando con hogueras, fuegos artificiales, bailes y danzas la festividad de San Fermín, así como también anduvieron repicando las campanas de su parroquia. Formándose "una danza al son de guitarra, y anduvieron bailando por las calles de San Lorenzo, Descalzos, San Francisco y San Antón hasta la plazuela del Consejo", y horas después todavía andaba "bulla de gente con mucha algazara diciendo: ¡Viva San Fermín de San

\footnotetext{
${ }^{10}$ ADP, Audiencia Episcopal. Procesos, C/ $1603-\mathrm{n}^{\circ}$ 6, fol. 2.

${ }^{11}$ AGN, Tribunales Reales. Procesos, núm. 10346, fol. 3.

12 AGN, Tribunales Reales. Procesos, núm. 100082, fol. 118.

13 AGN, Tribunales Reales. Procesos, núm. 91823, fol. 1.
} 
Lorenzo!, y ¡muera el de la Catedral y muera la ciudad y los que han traído el pliego!"14.

No obstante, si bien los momentos festivos (carnavales y festividades patronales) se mostraron como fechas realmente propicias para que surgiesen altercados del orden público en estos lugares. No menos proclives a degenerar en desórdenes fueron ciertas celebraciones religiosas, puesto que resultó sumamente frecuente que estallasen enfrentamientos durante las procesiones y romerías callejeras que tuvieron lugar en la Navarra moderna. Situación que se repitió en otros territorios según señalan Bernal ${ }^{15}$ y Mantecón ${ }^{16}$. En dichas ocasiones se puso de manifiesto no sólo la lucha por una posición social ante el resto de la comunidad, sino también rencillas y odios lastrados con el paso del tiempo. De este modo, en 1583 en la ciudad de Pamplona durante la procesión de las letanías, según indican los testigos a lo largo del proceso, se oyeron "ciertas voces y ruido de gente hacia la calle de las bolserías" ${ }^{17}$, en donde Miguel de Elzaburu fue agredido por Ojer de Echegoyen, Pedro de Gorrindo, Miguel de Larralde, Pedro Gabadi y Martín de Echarri.

Ya por último, completando el panorama de altercados que surgieron en estos enclaves urbanos debe ser destacado el uso de proclamas difamatorias ${ }^{18}$. Estas últimas no encontraron mejor espacio para publicitar sus sagaces y mordientes ataques que las calles. Es por ello que no extraña que en 1614 presentase la Marquesa de Falces una demanda contra Pedro Felipe de Echavarri, Dionisio de Arlas y Juan de Peralta como consecuencia de haber tomado parte en la confección de un libelo difamatorio dirigido a ella. Siendo "sus razones muy perniciosas y muy perjudiciales contra la honra y reputación de unos y de otros con que ofenden a muchas personas". Pero lo más interesante es que según algunos testigos, caso de Martín de Oñate, "se cantaba cierto escarramán y coplas contra el honor de la dicha marquesa y en ofensa de ella y de criados y adheridos suyos", indicando que estas coplas "se han cantado públicamente por las calles de la dicha villa de Peralta"19.

${ }^{14}$ AGN, Tribunales Reales. Procesos, núm. 91823, fol. 4.

15 Bernal Serna, L. M. (2003). «Los espacios de la violencia. Tabernas y fiestas en Vizcaya (1560-1808)». Vasconia, 33, p. 418. Véase también Bernal SERNA, L. M. (2007). op. cit., p. 44.

${ }^{16}$ MANTECón Movellán, T. A. (1997). Conflictividad y disciplimaniento social en la Cantabria rural del Antiguo Régimen. Santander: Universidad de Cantabria, p. 110.

${ }^{17}$ AGN, Tribunales Reales. Procesos, núm. 70037, fol. 3.

${ }^{18}$ Ruiz Astiz, J. (2012). La fuerza de la palabra escrita. Amenazas e injurias en la Navarra del Antiguo Régimen. Pamplona: EUNSA. (En prensa).

${ }^{19}$ AGN, Tribunales Reales. Procesos, núm. 14117, fol. 4. 
Podemos comprobar cómo un número muy destacado y sumamente variado de alteraciones del orden público se ocasionaron en las calles de muchas poblaciones navarras. En definitiva, a través de estos ejemplos se ha logrado constatar la pujanza de estos emplazamientos, lográndose apreciar que en éstos no sólo acontecieron enfrentamientos o agresiones físicas entre distintos grupos, sino que fueron el escenario primordial para emitir denuncias y quejas de un modo público para conocimiento de todo el vecindario. Por ello, la calle puede ser vista como un teatro en constante representación.

\section{PLAZAS: ESPACIO DE REUNIÓN Y DIVERSIÓN}

Otro espacio que adquirió un enorme protagonismo a lo largo de la Edad Moderna fue la plaza pública ${ }^{20}$. Esta última se erigió en uno de los lugares en donde se pusieron de manifiesto las relaciones intravecinales, y como consecuencia de ello también fue un punto especialmente proclive a experimentar altercados violentos. Ello es corroborado en el $21 \%$ de los casos en los que este escenario aparece en Navarra como el punto primordial en el que tuvieron lugar los altercados vecinales. Si bien es cierto que en ella acontecieron tres tipos de desórdenes públicos; aquellos que acontecieron fruto de las festividades locales (carnavales, fiestas patronales, romerías o procesiones), las rencillas vecinales como consecuencia de odios y rencores, y la fijación de escritos subversivos.

Tabla III. Desórdenes en las plazas públicas

\begin{tabular}{|c|c|}
\hline Tipo de disturbio & Número de sucesos \\
\hline Festividades locales & 37 \\
\hline Rencillas vecinales & 25 \\
\hline Escritos injuriosos & 9 \\
\hline Total & 71 \\
\hline
\end{tabular}

Primeramente conviene resaltar las pendencias y quimeras que con suma frecuencia estallaron entre distintas cuadrillas. Debido a ello no debe sorprendernos que, en 1636, se presentase una querella criminal contra Antonio de Santa Lucía, Pedro de Sangariz, Marco de Udi y Sebastián de Arpentat, vecinos de la villa de

\footnotetext{
${ }^{20}$ Véanse a este respecto los trabajos de MuchembLED, R. (1994). Société, cultures et mentalités dans la France moderne, XVIe-XVIIIe siècle. Paris: Armand Colin, p. 76; RodRíGUEZ SÁnCHEZ, A. (1995). op. cit., p. 121; MARTínEZ GIL, F.; RodRÍGUEZ GONZÁLEZ, A. (2004). «La fiesta en el mundo rural (siglos XVII-XVIII)». MARTínEZ-BuRgos, P.; RodríGUEZ GONZÁLEZ, A. (coords). La fiesta en el mundo hispánico. Cuenca: Universidad de Castilla-La Mancha, p. 289; Bernal SERnA, L. M. (2003). op. cit., p. 423; Gil MASSA, J. A. (2003). op. cit., p. 434; FARGE, A. (2008). Efusión y tormento. El relato de los cuerpos. Historia del pueblo en el siglo XVIII. Madrid: Katz, p. 74; MENDOZA GARRIDO, J. M. (1999). op. cit., p. 162.
} 
Aibar. ¿Las causas? Los demandados fueron acusados de provocar un motín entre los habitantes de Sada al injuriarles gravemente, ya que parece ser que el 13 de noviembre "una docena de hombres" estuvieron "causando motín para con los vecinos", lo que pudo provocar que "sucedieran muertes". Según Lope García, jurado, aquéllos iban diciendo a voz alta e inteligle: “¡Ea pecheros!, ¡Villanos de la gallina blanca!, ¡Salid aquí si sois hombres!”, repitiéndolo en varias ocasiones. El declarante señala que "les dijo que mirasen lo que decían porque en la dicha villa nadie debía pecha y que si alguno lo debía ellos debían de verlo", momento en el que los acusados "rancando las dagas que tenían acudieron para este testigo unos por herir y matarle", mientras otros fueron "defendiéndole y deteniéndolos"21. Pero es Martín Vicente Sastre quien sostiene que éstos "llegaron de paso a la dicha plaza, cosa de una docena de hombres con sus azadones", quienes se dedicaron a decir "con grave injuria y agravio" de los vecinos: ¡Ea bellacos, villanos, pecheros de la gallina blanca!", todo lo cuál lo acometieron "tocando una corneta" y "causando alboroto y motín entre la gente de la villa" "2 . Un suceso similar tuvo lugar el 21 de julio de 1744 en Corella, en donde se produjeron varias pendencias "en la plaza de Nuestra Señora del Rosario y en la que llaman de las Verduras"23. Como consecuencia de ello resultó herido Pedro de Samaniego al enfrentarse su cuadrilla -conformada por Juan Antonio Serrano, Martín de Monforte, Miguel Virto, Miguel Lacarra, Miguel Rincón y Miguel de Monreal- con otros vecinos entre los que destacan Pedro de Funes, Antonio de Ochoa y Ramón Ferranz.

Gráfico III. Altercados originados en las plazas

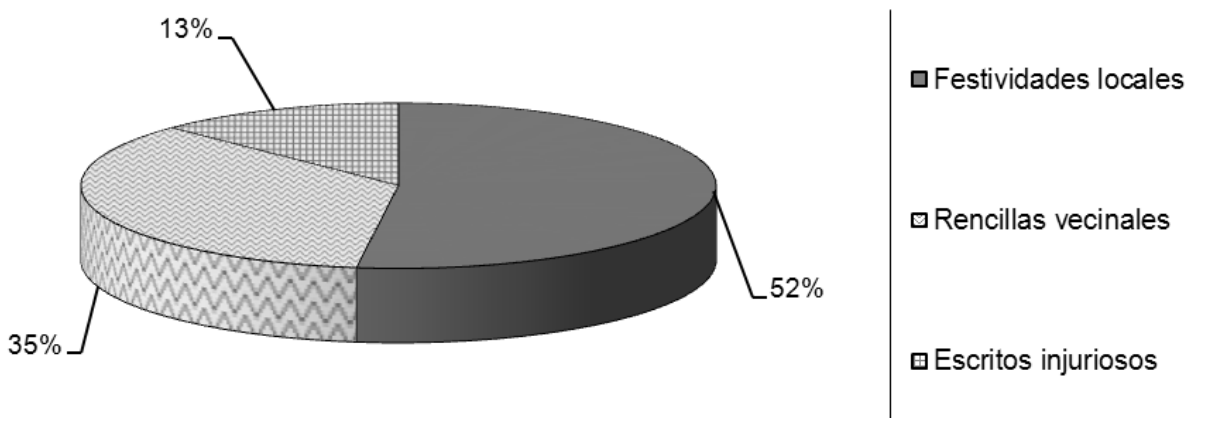

${ }^{21}$ AGN, Tribunales Reales. Procesos, núm. 102076, fol. 3.

${ }^{22}$ AGN, Tribunales Reales. Procesos, núm. 102076, fol. 5.

${ }^{23}$ AGN, Tribunales Reales. Procesos, núm. 126964, fol. 2. 
Sin embargo, en segundo lugar, si hubo sucesos que estallaron con cierta frecuencia en las plazas de cada localidad estos fueron los que surgieron en los momentos festivos. La ocasión se mostraba propicia para que fruto del divertimento y el jolgorio propio de aquellas fechas se ocasionasen enfrentamientos vecinales. Entre los festejos que pueden ser localizados en estos lugares nos encontramos con los carnavales, por lo que no nos debe extrañar la queja que se interpuso en 1553 en Larraga. En dicha localidad, según Jorge Pérez, "el regimiento las noches de carnestolendas han acostumbrado y acostumbran hacer vedamiento que ninguno salga de noches ni ande por las calles de la dicha villa con armas so pena de perderlas y otras penas" ${ }^{24}$. Pese a ello, Pedro Pardo sostiene que una de aquellas noches "sintió dar voces en la plaza y haber cuestión y riña", a lo que fue hasta allí y encontró a "Antón de Mateo y Jorge Ibáñez, su hijo, que habían reñido con Miguel de Lesaca" 25 . En otras ocasiones las fiestas patronales también degeneraron en alteraciones del orden. De esta manera, el 23 de julio de 1592 en la villa de Ablitas en las fiestas en honor a Santa María Magdalena se produjo cierto tumulto provocado por Jerónimo López, Domingo de Haya, Juan de Salazar, Miguel López, Alonso Pablo, Francisco de Arguedas, García de Falces, Floristán de Antillón, Diego Jiménez, Francisco Irazabal, Bernardino López, Juan de Pamplona, Pedro Martín, Pedro de Galipienzo, Martín de Cunchillos, Francisco Calvillo, Martín Marco, Sebastián García, José Penín, Felipe Sanz y Pedro de Berberana, vecinos de Cascante. Todos ellos "revolvieron y amotinaron la gente", causando "motín público" y que "sucedieran muertes y heridas y otros notables daños" 26 . Los excesos provocados por éstos surgieron cuando, según Martín de Cegama, estaban el alcalde y los regidores de Ablitas junto con otros vecinos recogiendo el ganado que iba a servir luego para los festejos taurinos. Allí se encontraban Jerónimo López y Miguel López, hermanos, "a un lado en la plaza juntamente con Floristán de Antillón, García de Falces, Domingo de Haya y otros vecinos de Cascante". Este testigo sostiene que mientras elegían los toros que después iban a ser lidiados los acusados "les dieron con sus picas no dejando estar quietos para que fuesen escogidos" y pese a que les rogaron en repetidas ocasiones que "no les picasen y les dejasen escoger los dichos toros no quisieron hacerlo, antes les picaban más a menudo". Poco tiempo después "cayó un novillo en el suelo y Miguel López le cogió de la cola”, a lo que llegó Antón de la Paz, vecino de Ablitas, y le dijo "que le dejase estar", sin embargo "Miguel López con mucha cólera y enojo le respondió que no quería y echó mano a su espada contra Antón”,

\footnotetext{
${ }^{24}$ AGN, Tribunales Reales. Procesos, núm. 86328, fol. 5.

${ }^{25}$ AGN, Tribunales Reales. Procesos, núm. 86328, fol. 7.

${ }^{26}$ AGN, Tribunales Reales. Procesos, núm. 39799, fol. 2.
} 
y enseguida "llegaron todos los dichos de Cascante a la plaza cada uno mano a su espada" ${ }^{27}$. Y completando el panorama de festejos comunitarios que se desarrollaron en las plazas públicas de cada localidad debemos tener en cuenta la celebración de los mayos, ocasión que se mostró muy proclive a degenerar en estallidos violentos. Tanto es así que el 29 de mayo de 1674 en la localidad de Muez se produjeron entre las nueve y diez de la noche varios disparos de arcabuz, y como consecuencia de éstos hubo algunas personas heridas. Juan Pérez de Iturgoyen, Juan Martínez de Villanueva y Diego Segura fueron interrogados sobre las causas por las que lanzaron diversas pedradas a la casa de Martín de Guembe, regidor local. Los tres afirmaron que aquella noche "se hallaron en la plaza del dicho lugar que junto al mayo que hay en ella", estando todos ellos "en compañía de otras personas gozando del festejo" en donde había "hogueras y tiros de arcabuces". Fue entonces cuando Martín de Guembe "tiró un tiro de perdigones de la puerta de su casa que está pegante a dicha plaza", alcanzándole a Villanueva "en las dos piernas y junto a la planta del pie con muchos perdigones" 28 . También Miguel de Larumbe, testigo, señaló que fue Martín de Guembe "sin causa ni motivo alguno que para ello le dieran estando en la puerta de su casa que está pegante a la dicha plaza tiró con un arcabuz un tiro de perdigones a Juan Martínez de Villanueva y Diego Segura, y de él se hallan heridos"29.

Para concluir, en tercer caso, deben resaltarse otros sucesos que emplearon las plazas para dar mayor publicidad a sus quejas y demandas. Me estoy refiriendo a la aparición de libelos y pasquines, puesto que estos soportes trataron de influir y crear estados de opinión, por lo que tendieron a aparecer fijados en puestos de cierta significación a escala local. Esto último es lo que sucedió en Fitero, ya que allí el 7 de diciembre de 1586, "al tiempo que amaneció se hallaron en la plaza de la dicha villa cinco papelones o pliegos de papel en la pared de la casa de Pedro de Gómara", aquéllos estaban "puestos en una caña de vara y media con dos clavos grandes hincados en cada uno de los dichos papelones" y había sido pintada "con tinta negra un aspa, a manera de sambenito". Uno de éstos tenía escrito en la parte de arriba "dásele las ejecutorias" y abajo en dos renglones "Miguel Gómez en sambenito", en otro decían "Andrescilo de Cuenca, sobrino de un quemado", otro contenía "Juan Navarro y Sebastián Navarro, nietos de un quemado", y en el último se referían a "Diego de Sebastián, nieto de un sambenitado" ${ }^{30}$.

\footnotetext{
${ }^{27}$ AGN, Tribunales Reales. Procesos, núm. 39799, fols. 11-12.

${ }^{28}$ AGN, Tribunales Reales. Procesos, núm. 4277, fol. 1.

${ }^{29}$ AGN, Tribunales Reales. Procesos, núm. 4277, fol. 3.

${ }^{30}$ AGN, Tribunales Reales. Procesos, núm. 99125, fol. 526.
} 
Tras analizar algunos de los disturbios que se ocasionaron en las plazas públicas de cada localidad lo que se pone de manifiesto es que en ellas estallaron determinados desórdenes públicos. La variedad que nos mostraban las calles ya no se registra para las plazas. Pese a ello, se ha logrado evidenciar que acontecieron con cierta frecuencia numerosas pendencias y quimeras vecinales, así como todo tipo de encontronazos propios de los momentos de diversión (carnavales, fiestas patronales y mayos).

\section{ESPACIOS SAGRADOS: RECOGIMIENTO VERSUS CONFLICTIVIDAD}

Hasta ahora hemos hecho referencia a espacios típicos y muy característicos en los que no resultó nada extraño que surgiesen enconados enfrentamientos entre vecinos. Sin embargo, tampoco podemos olvidarnos de los conflictos que estallaron en lugares que en principio debían estar regidos por la calma y el recogimiento. Dentro de éstos cabe destacar los recintos religiosos. Sin duda, los templos se mostraron en algunas ocasiones como los escenarios más propicios para manifestaciones violentas ${ }^{31}$. Bien se tratase de enconadas disputas entre miembros del vecindario, de la aparición de proclamas difamatorias dirigidas contra clérigos, así como de motines de carácter antiseñorial.

Tabla IV. Desórdenes en los espacios religiosos

\begin{tabular}{lc}
\hline \multicolumn{1}{c}{ Tipo de disturbio } & Número de sucesos \\
\hline Rencillas vecinales & 18 \\
Escritos injuriosos & 9 \\
Motines antiseñoriales & 3 \\
\hline \multicolumn{1}{c}{ Total } & 30 \\
\hline
\end{tabular}

En este tipo de emplazamientos se puso de manifiesto las tensiones locales que existieron, principalmente, en torno a la jerarquía vecinal que se traducía en el orden de los asientos que cada uno debía de guardar durante la celebración de los divinos oficios. Un caso muy elemental es el que nos encontramos en 1581 en Tafalla. Allí Arnau Berges, maestro de escuela, tras entrar en la iglesia se sentó en los puestos que les correspondían a los regidores de la villa. Visto esto le mandaron en repetidas ocasiones que se levantase "porque aquel asiento era para el

${ }^{31}$ Sobre su importancia como escenario de disturbios contamos con los trabajos de MANTECón Movellán, T. A. (1997). op. cit., p. 106; MuCHEMBled, R. (1994). op. cit., p. 77; RodRíGueZ SÁNCHEZ, A. (1995). op. cit., p. 121; BERNAL SERNA, L. M. (2003). op. cit., p. 423. 
regimiento" ${ }^{32}$ y ante su reiterada negativa se produjo un alboroto en toda la iglesia con el objeto de intentar desplazar a Berges del sitio que estaba ocupando.

Gráfico IV. Altercados originados en los espacios religiosos

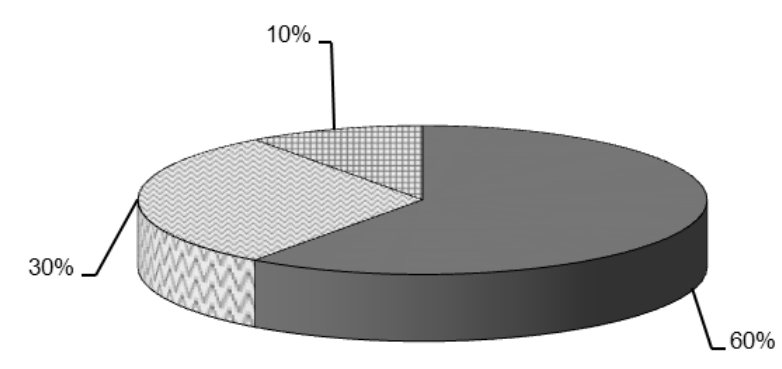

口Rencillas vecinales

๑Escritos injuriosos

घMotines antiseñoriales

Por otro lado, tampoco resultó extraño que estallasen motines durante la celebración de los divinos oficios entre los vecinos de una misma localidad fruto del odio y la animadversión existente entre diferentes facciones. Así puede explicarse que a finales de abril de 1534 en Carcastillo se produjese cierto altercado en la iglesia parroquial entre Pedro Jiménez y Miguel de San Juan, a lo que enseguida "comenzaron a reñir y alborotarse todos los del dicho pueblo, los unos a favor de uno y los otros a favor del otro". Viendo este suceso el alcalde "mandó a los dichos Pedro Jiménez y Miguel de San Juan que se fuesen a sus casa porque no se siguiese algún escándalo", pero Jiménez le respondió "que no quería y que por él no saldría de la dicha iglesia", lo que provocó que le agarrase del brazo y le dijese "Pedro Jiménez, anda salid e iros a vuestra casa y cumplid lo que yo os he mandado". Cuando lo llevaba del brazo apareció Luis Jiménez "muy airado y alborotado" y le dijo "¡voto a Cristo no saldrá de aquí!” y el alcalde replicó "sí saldrá", y Jiménez espetó "no saldrá por vos", y sacando su espada le intentó herir al alcalde "y le arrojó diversos golpes e hizo lo que era en sí por herir y matar al dicho alcalde y lo hubiera hecho por efecto sino le hubieran impedido algunos que presentes se hallaron que le asieron del brazo y le detuvieron que no le hiriese",33. Acto seguido prendió a Luis Jiménez diciéndole "preso por el rey", momento en el que "salieron en alborote todos los dichos acusados armados contra el dicho alcalde y otros muchos deudos y parientes de los dichos Pedro Jiménez y Luis Jiménez". Entre aquellos cabe destacar a Pedro Jiménez, Luis Jiménez, Martín Guillén, Juan

\footnotetext{
${ }^{32}$ AGN, Tribunales Reales. Procesos, núm. 119349, fol. 7.

33 AGN, Tribunales Reales. Procesos, núm. 207, fol. 16.
} 
Guillén, Martín Paris, Juan Salvador, Martín Jiménez, Blasco Jiménez, Miguel de Villafranca y Miguel San Juan, diciéndole todos ellos "que soltase el preso"34.

Incluso los desórdenes que estallaron en el interior de los recintos religiosos tuvieron en numerosas ocasiones como destinatarios a los religiosos locales. Esto es lo que sucedió en Salinas de Pamplona en 1570, donde se produjo cierto altercado contra Lope de Salinas, rector de la parroquia. Según la costumbre local parece ser que en los últimos dieciséis años habían nombrado un año al vicario los miembros del estado de hidalgos y al siguiente los labradores. Este año el turno correspondía a los primeros, y pese a tener ya elegido el sustituto llegaron a finales de noviembre sin ver satisfechas sus demandas. Esta situación ocasionó que el 3 de diciembre se originase un tumulto cuando Lope de Salinas se dispuso a leer en alto la provisión que García de Arrarás, notario de la Curia Eclesiástica, le había entregado de parte del Vicario General para que continuase ejerciendo su oficio. En ese mismo momento, según Martín de Iraizoz, "se levantaron de sus asientos Juan Guillén y Juan Miguel de Larra", quienes fueron hasta el altar "estorbándole que no diese", a lo que el vicario les dijo en repetidas ocasiones que "le dejasen hacer sus oficios conforme su superior se lo mandaba" ${ }^{\text {"2 }}$. Mientras, según Miguel de Iriarte, ambos estaban "dándole muchos empetones y golpes"36. Poco después Juan Guillén ordenó a un muchacho, hijo de García de Ochoa, "que fuese por los compañeros corriendo para que viniesen a la dicha iglesia", entre aquellos se encontraban "García de Ochoa, Juanot de Azme y Miguel de Errasti". Todos ellos "con mucha cólera y alteración y voces se llegaron juntos", subieron al altar y "dándole de empujones [al vicario] le hicieron bajar de las gradas" y de este modo "le impidieron que no dijese la misa" ${ }^{, 37}$.

Tampoco debería sorprendernos que, en ocasiones, fruto del fervor contra la jurisdicción señorial de una determinada localidad la multitud enfurecida decidiese asaltar un monasterio. Ello sucedió el 22 de junio de 1675 en la localidad de Fitero, en donde estalló un motín contra los religiosos locales que se alargó hasta la jornada siguiente. La tarde de aquel día se celebró una procesión alrededor de las naves de la iglesia que fue reprendida por varios vecinos con el lanzamiento de piedras mientras les gritaban a los frailes "pícaros, tiranos, sayones y crueles". Fruto de aquellas pedradas fueron heridos los padres Ignacio de Ostabat, Francisco Jordán e Isidoro Fernández de Urdañez. Sin embargo, fue durante la noche cuando

\footnotetext{
${ }^{34}$ AGN, Tribunales Reales. Procesos, núm. 207, fol. 17.

${ }^{35}$ AGN, Tribunales Reales. Procesos, núm. 10976, fol. 72.

${ }^{36}$ AGN, Tribunales Reales. Procesos, núm. 10976, fol. 92.

${ }^{37}$ AGN, Tribunales Reales. Procesos, núm. 10976, fol. 76.
} 
una multitud "fue por las calles dando voces a son de caja en forma de tumulto", desórdenes que continuaron durante la mañana del 23, puesto que "anduvieron con la caja de la misma suerte diciendo que habían de presentarse al señor Don Juan de Austria para ir a servir al rey nuestro señor". El objetivo de aquella turba era el monasterio, por ello "se encaminó todo el motín hacia el convento" y cuando llegaron "a las puertas se oía ruido de "mueran" con muchas palabras afrentosas". Finalmente lograron entrar en el recinto religioso en número de "pasadas de quinientas personas" entre hombres y mujeres. Los monjes viendo aquello "procuraron escapar por donde pudieron", así unos se retiraron al coro escondiéndose debajo de sus sillas, otros se resguardaron en el desván y algunos se lanzaron por las ventanas al olivar contiguo, pero "a este tiempo ya estaba el olivar lleno de hombres y mujeres corriendo con espadas desnudas, asadores y palos" ${ }^{38}$. Hubo monjes - entre los que se encontraron Martín de Labayen, Clemente de Oñate, Joan de Arnedo, Gregorio Alfonso, Celedón de Espinosa, Guillermo de Arbizu, José Zapata, Luis de Olleta, Jerónimo de Olloqui, Nicolás de Ardanaz y Dionisio de la Torre- que enseguida fueron encontrados por los acusados, siendo apartados por "las mujeres a empellones de la compañía de su soberano señor, y a pellizcos y puñadas los querían matar diciéndoles tantas insolencias en su presencia que pidiéndole justicia y misericordia decían: ¡estos pícaros se lo merecen!, ¡estos perros tienen la culpa!". Lo cierto es que hubo mujeres "tan desatentas que las juzgaron dichos padres espiritadas", mientras una de ellas "se puso en el corillo del órgano y con una espada desenvainada amenazaba a los religiosos". Cuando terminaron sus acciones "profanaron todo el monasterio, sin dejar coro, dormitorios, refectorio, cocina, enfermería y hospedería, hasta saquear las tres últimas oficinas hurtándoles las sábanas y camisas y rompiendo con palos cuanta vasija toparon y desquiciando con vigas y troncos las puertas de las celdas de los religiosos" 39 .

Para concluir, debe reseñarse que los espacios sagrados también se erigieron en un lugar predilecto en el que proceder a la colocación de hirientes ataques a los miembros del clero local. Es por ello por lo que son abundantes los casos de libelos y pasquines que amanecieron fijados en las puertas de las parroquias o en los pilares de los atrios. Uno de estos ejemplos lo encontramos en la localidad de Genevilla, en donde el 4 de enero de 1583 apareció "en la puerta de la iglesia" un "escrito con muchas cosas feas e indecorosas en agravio y deshonor de Domingo

\footnotetext{
${ }^{38}$ AGN, Tribunales Reales. Procesos, núm. 4333, fol. 1.

${ }^{39}$ AGN, Tribunales Reales. Procesos, núm. 4333, fol. 2.
} 
Martínez y otras personas a manera de libelo difamatorio" 40 . Conteniéndose en éste, según Juan Díaz de Marañón, el siguiente aviso:

Quienes os ha puesto no ha venido de Viana, que no hubo el día domingo víspera de año nuevo cuando el vicario predicó no había sino dos hombres de fuera que eran el uno Juan de Labastida, yerno de la mayoría de vecinos de Genevilla, y Cristóbal de Villanueva, vicario yerno de Juan de Arrieta ${ }^{41}$.

Vistos los diferentes altercados que se originaron en torno a los recintos de carácter religioso se comprueba que pese a representar únicamente el 9\% de los pleitos que se han examinado, nos reflejan una riqueza de tipologías muy interesante. A lo que debe añadirse para completar el panorama que en estos espacios se ha podido constatar que estallaron tanto disturbios dirigidos contra los propios clérigos como contra civiles.

\section{AYUNTAMIENTOS Y CONCEJOS: IMAGEN DE LA REPRESENTA- CIÓN SOCIAL Y POLÍTICA}

Los lugares de representación política a escala comunitaria, caso de los ayuntamientos y concejos, también se mostraron como un lugar proclive a generar enfrentamientos vecinales. En aquéllos, pese a la idea que pueda tenerse de orden y control, se sucedieron de un modo continuado los desórdenes y tumultos como consecuencia de las decisiones que en ellos se acordaban. Pero fue, sobre todo, durante el proceso de elección de cargos municipales que se celebraban en su interior cuando acontecieron la mayor parte de estos disturbios. Entre los 27 disturbios que se han constatado en este tipo de emplazamientos se han evidenciado tres categorías de desórdenes públicos: rencillas vecinales, desacato a las autoridades y publicación de escritos injuriosos.

Tabla V. Desórdenes en ayuntamientos y concejos

\begin{tabular}{cc}
\hline Tipo de disturbio & Número de sucesos \\
\hline Rencillas vecinales & 14 \\
Desacato a las autoridades & 10 \\
Escritos injuriosos & 3 \\
\hline Total & 27 \\
\hline
\end{tabular}

En nuestro caso la insaculación de oficios se mostró en muchas ocasiones como el detonante que provocó que en los ayuntamientos se originasen sucesos

\footnotetext{
${ }^{40}$ AGN, Tribunales Reales. Procesos, núm. 282290, fol. 3.

${ }^{41}$ AGN, Tribunales Reales. Procesos, núm. 282290, fol. 34.
} 
violentos $^{42}$. Lo que no sólo sucedió en Navarra, puesto que Bernal ${ }^{43}$ también indica la existencia de casos idénticos en Vizcaya durante la Edad Moderna. La problemática que se generó en estos emplazamientos se puede comprobar a través de diversos ejemplos, ya que no cabe duda de que el sistema insaculatorio consolidó un constante juego de intrigas y disputas por alcanzar el poder, por lo que no debe extrañarnos que se originasen distintos altercados en ciertas ocasiones. De este modo, merece la pena destacar que en la localidad de Arellano se reprodujeron determinados alborotos en 1565 con motivo de la elección de nuevos jurados. Dicha población tenía "uso y costumbre de nombrar jurados primeros día de año nuevo en cada un año". De este modo, Juan González, jurado, apareció en el concejo para hacer el nombramiento de jurados y alcaldes "diciendo que tenía el voto de Martín Sanz de Igúzquiza, jurado que estaba mal dispuesto en la cama”. Ante esta situación Juan de Sarasa le dijo "que le parecía mal en semejante concejo venir con falsa información dando a entender cosa por otra". Acto seguido Juan González "le dijo muchas palabras injuriosas, diciendo que él no tenía que hacer en concejo" y un hermano suyo llamado Pedro González "desmintió dos y tres veces" a Sarasa "diciendo que mentía y que valía (su hermano) más que el dicho Juan de Sarasa y que era mejor y otras palabras feas e injuriosas". Acto seguido Diego de Medrano trató de defender a Sarasa y como consecuencia de ello "le maltrataron en su persona dándole golpes y empetones con efusión de sangre de los brazos y cara"44. Luis Felipe, testigo, señala "que estaban en el dicho concejo y se revolvieron y daban voces unos contra otros, en que vio a Pedro González que asió de Diego de Medrano y le dio de empujones apartándole del dicho concejo, dándole un golpe con mucha alteración" 45 . Juan de Azcoitia indica que "vio que se revolvía la gente y que Pedro González le dijo a Juan de Sarasa: yo soy tan bueno como vos"46. Martín Sanz sostiene que "no le había dado tal comisión a Juan González, antes habían nombrado a Diego Martínez y le había dicho que nombrase alcalde y jurados a otros de los que el dicho Juan González había nombrado y que no consentía ni un fin en el nombramiento" "47. Finalmente se nombró como alcalde a Diego de Mendoza y por jurados a Martín González y a Juan Martínez. Pese a ello, ante la oposición del Estado de Hidalgos se procedió a una nueva elección en

42 RuIz Astiz, J. (2010). «Régimen insaculatorio y conflictividad en la Navarra del Antiguo Régimen». Letras de Deusto, 40-129, pp. 53-75.

${ }^{43}$ Bernal SERnA, L. M. (2007). op. cit., p. 44. Véase también Bernal SERnA, L. M. (2003). op. cit., p. 423.

${ }^{44}$ AGN, Tribunales Reales. Procesos, núm. 67242, fol. 1.
${ }^{45}$ AGN, Tribunales Reales. Procesos, núm. 67242, fol. 2 .
${ }^{46}$ AGN, Tribunales Reales. Procesos, núm. 67242, fol. 3.
${ }^{47}$ AGN, Tribunales Reales. Procesos, núm. 67242, fol. 10. 
la que resultaron elegidos García de las Peñas como alcalde, y por jurados Juan de Medrano y Juan de Riezu. Sin embargo, Juan González dijo que "no consentía el nombramiento por cuanto aquél era en perjuicio del concejo de hidalgos y contra el uso y costumbre que tenía y que ya estaba hecha la elección y con consentimiento de todo el concejo de los hidalgos"48. Martín de las Peñas nos señala que "trataron palabras de enojo entre Juan de Sarasa y Pedro González", entre las que Sarasa le dijo que la elección hecha por el concejo de hidalgos "había sido hecha con bellaquería" ${ }^{49}$. A su vez, otro de estos casos nos lo encontramos en la localidad de Aoiz, hasta donde se trasladó en enero de 1609 el juez insaculador para proceder a la elección de los cargos municipales del próximo año. El problema llegó "después que se acabaron de decir los nombres de aquellos que estaban insaculados en bolsa de alcaldes", fue entonces cuando Juan de Monreal, Martín de Monreal, Miguel de Burdaspar y Juan Martínez comenzaron a quejarse. Fruto de ello "se revolvió la gente que había en la dicha sala levantándose de los asientos"50.

Gráfico V. Altercados originados en ayuntamientos y concejos

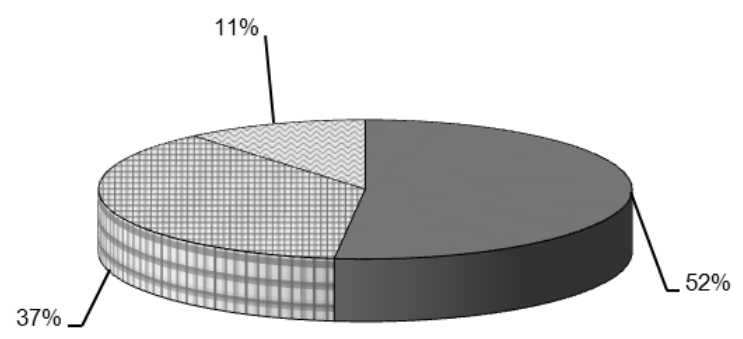

口Rencillas vecinales

๑Desacato a las autoridades

घEscritos injuriosos

No obstante, en otras ocasiones los altercados que se originaron en los ayuntamientos o concejos no tuvieron nada que ver con el modelo insaculatorio, puesto que en determinadas poblaciones funcionó para algunos cargos la designación directa. Fue por ello por lo que en 1588 se presentó una queja criminal en la localidad de Valtierra por parte de Pedro Laguado, Pedro de Aguirre y Juan Martínez contra Juan de Beaumont, Pedro de Ulibarri, Juan de Aguirre y Batista Bartolomé. Fue Pedro de Añorbe el encargado de juntar al vecindario en el concejo para designar, en nombre de la villa, una persona para un beneficio que estaba vacante tras el fallecimiento de Francisco de Lesaca. Durante su celebración Juan

${ }^{48}$ AGN, Tribunales Reales. Procesos, núm. 67242, fol. 26.

${ }^{49}$ AGN, Tribunales Reales. Procesos, núm. 67242, fol. 28.

${ }^{50}$ AGN, Tribunales Reales. Procesos, núm. 57539, fol. 4. 
de Beaumont entró en el concejo que se estaba efectuando y cuando le dijeron que se fuese de allí porque no tenía facultad ni derecho para impedir el nombramiento "se levantó muy enojado y alborotado, y sin que dejase de leer el requerimiento dijo a públicas voces: ijuro a Dios que mienten!", ante lo "se levantó toda la gente que estaba en el dicho concejo muy alborotados con ánimo de pendencia"51. Valentín de Otazu sostiene que "Juan de Beaumont muy airado y con alta voz volviendo el gesto diciendo que mentían", a lo que acto seguido este testigo vio que "se alborotó todo el concejo y se salieron por la puerta de fuera",52. Pese a ello, finalmente, no sucedió nada.

Al margen de los encontronazos que se ocasionaron fruto de la elección o del nombramiento de nuevos cargos municipales, tampoco extrañará el hecho de que en determinadas poblaciones el vecindario fuese extremadamente celoso de sus competencias, alterándose frente a cualquier novedad o decisión que considerasen que resultaba perjudicial para todos ellos. Fue por ello por lo que el 29 de diciembre de 1720 en Puente la Reina estalló un alboroto en el ayuntamiento de la localidad. En dicha jornada se puso "en candela el cántaro garapito ${ }^{53 "}$ y tras ser leídas las condiciones de su arriendo "al punto que se acabó de leer aquella empezaron a inquietarse José de Ollo, Diego de Azcárate, Juan Francisco de

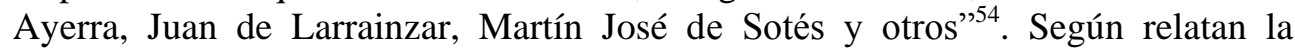
mayoría de los testigos presentados "muchos vecinos se pusieron en pie e impidieron que se continuase con la lectura de los mandatos del Real Consejo", lo que provocó que Juan Manuel de Garro, alcalde, y los regidores se fuese "a otra sala del tribunal en donde pese a ello el griterío era ensordecedor y con el objeto de evitar mayor tumulto desalojó la sala"55. ¿Por qué se produjo este altercado? El motivo primordial puede rastrearse en los gritos que profirieron "a una voz", puesto que según ellos "ni la villa ni el Consejo podían nombrar persona para

${ }^{51}$ AGN, Tribunales Reales. Procesos, núm. 148187, fol. 5.

52 AGN, Tribunales Reales. Procesos, núm. 148187, fol. 9.

53 Garapito: "Palabra típica de Navarra. Arbitrio o impuesto sobre la exportación, que grava las operaciones de medición y carga de vinos, vinagres y aguardientes que se extraigan de la localidad. A la vez que un arbitrio antiquísimo y de muy buenos rendimientos, es un servicio municipal para facilitar las operaciones de venta y exportación de los líquidos sujetos al pago, toda vez que el rematante del arriendo (garapitero) queda obligado a mostrar a los compradores las bodegas o almacenes donde haya líquidos para la venta, a practicar la medición con las vasijas o medidas oficiales, llevando la cuenta de lo medido, y por último, a liar y cargar los envases". (Vocabulario Navarro. Iribarren, p. 251).

${ }^{54}$ AGN, Tribunales Reales. Procesos, núm. 91887, fol. 1.

${ }^{55}$ AGN, Tribunales Reales. Procesos, núm. 91887, fol. 17. 
enseñar los vinos a los arrieros, sino que dicha nominación tocaba a los vecinos de la villa""56.

Completando el panorama de desórdenes públicos que estallaron en ayuntamientos y concejos debo destacar, para finalizar, las proclamas difamatorias que fueron fijadas en ellos para denunciar a ciertos personajes. Los edificios representativos de la autoridad local, al igual que hemos comprobado para los recintos religiosos, fueron propicios para que los autores de libelos y pasquines decidiesen dar a conocer sus ataques y críticas a toda la comunidad, ya que se trató de lugares emblemáticos y punto de encuentro en muchas ocasiones. Ello puede apreciarse en algunos casos, como el que tuvo lugar en Barasoain en junio de 1729, donde se presentó una querella criminal contra José Olcoz y Jerónimo Celaya por ser los autores de unos escritos denigrativos contra la persona de José Antonio de Baquedano. En los "soportales del ayuntamiento" aparecieron varios pasquines contra este personaje entre el 24 y 28 de dicho mes "con unas letras crecidas y torcidas" donde se "decía muchas desvergüenzas"

En definitiva, de todos los diferentes tipos de altercados que han sido reseñados que acontecieron en los lugares de representación política, como eran los ayuntamientos y concejos, se ha puesto de manifiesto la enorme relevancia que tuvieron los desórdenes que surgieron como consecuencia de la elección de nuevos cargos municipales. En total los disturbios que surgieron en estos emplazamientos representan un $8 \%$ de los casos que han sido estudiados. Sin embargo, lo que se deduce de este análisis es que en ellos no existió una gran diversidad de conflictos, ya que la práctica totalidad de éstos se ocasionaron fruto de las ansias de poder que detentaron ciertas familias por lograr conseguir controlar y dirigir la actividad política de sus respectivas comunidades, de ahí la importancia de los nuevos cargos electos.

\section{ZONAS EXTRAMUROS: ESPACIOS QUE ESCAPAN AL CONTROL DE LAS AUTORIDADES}

En este caso deseo resaltar los desórdenes públicos que se produjeron en caminos y campos, zonas todas ellas apartadas de los núcleos poblacionales. Sin ningún género de dudas estos lugares fueron propicios para que en ellos se originasen reyertas y pendencias entre vecinos, sobre todo durante el periodo

\footnotetext{
${ }^{56}$ AGN, Tribunales Reales. Procesos, núm. 91887, fol. 18.

${ }^{57}$ AGN, Tribunales Reales. Procesos, núm. 32749, fol. 9.
} 
nocturno ${ }^{58}$. Entre los enfrentamientos que se han localizado nos encontramos con dos tipologías: los que surgieron en torno a festividades locales y aquellos que se ocasionaron fruto de enemistades y odios entre vecinos.

Tabla VI. Desórdenes en zonas extramuros

\begin{tabular}{cc}
\hline \multicolumn{1}{c}{ Tipo de disturbio } & Número de sucesos \\
\hline Festividades locales & 12 \\
Rencillas vecinales & 9 \\
\hline Total & 21 \\
\hline
\end{tabular}

Gráfico VI. Altercados originados en zonas extramuros

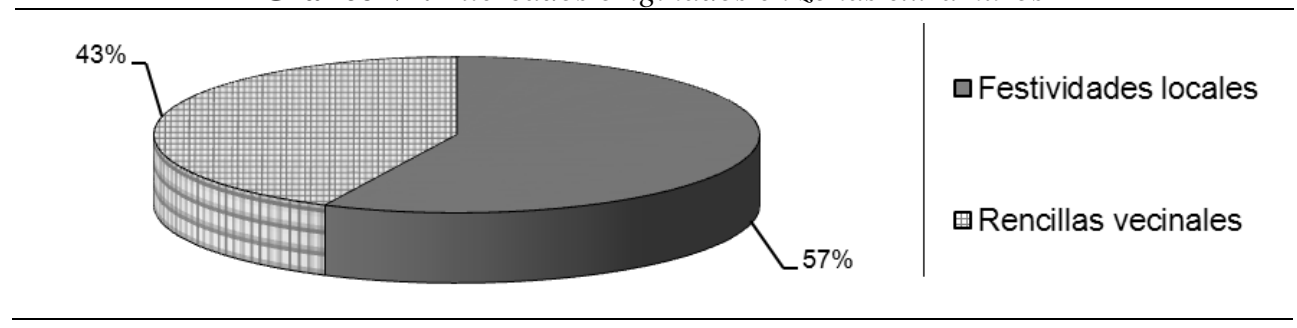

Cabe destacar que el mayor número de casos que se sucedieron en dichos puntos obedecieron a causas concretas como las celebraciones festivas. Dentro de todas ellas nos encontramos, en primer lugar, con las romerías, procesiones y peregrinaciones a los santuarios locales. Así sucedió, por ejemplo, en 1549 un enfrentamiento armado durante la procesión que la localidad de Villafranca organizaba todos los años por el mes de junio a la ermita de Nuestra Señora de Arlás. En dicho año, yendo como siempre "por el camino real" ${ }^{59}$ fueron atropellados por cuatro hombres de armas que iban montados en sus respectivos caballos sembrando el temor entre los vecinos de Villafranca, aunque finalmente les hicieron frente y huyeron rápidamente por el monte. Junto a ello, en segundo lugar, deben ser mencionadas dentro de las festividades locales los sucesos que se originaron en las fiestas patronales de muchos pueblos navarros. Durante su desarrollo resultó bastante habitual que surgiesen rencillas fruto de cualquier malentendido, el cuál terminaba gestándose en un nuevo altercado. Un claro ejemplo de esto nos lo encontramos en la localidad de Meoz, en el Valle de Lónguida, en donde la tarde del 29 de junio (San Pedro) de 1800 se produjo una

58 Consúltense las apreciaciones que ofrecen en sus trabajos MANTECón Movellán, T. A. (1997). op. cit., p. 99; FARGE, A. (2008). op. cit., p. 131; BernAl SERnA, L. M. (2003). op. cit., p. 423.

${ }^{59}$ AGN, Tribunales Reales. Procesos, núm. 95800, fol. 6. 
pendencia entre varios mozos de este lugar y otros de la vecina villa de Aoiz. Nicolás Xavier Reclusa, testigo, sostiene que "con motivo de la festividad de mecetas que se celebró el día de San Pedro Apóstol" los mozos de la localidad tuvieron "gaita por la tarde estando tañendo y bailando en las eras de la parte de arriba de la iglesia". Entre las seis y siete de aquella tarde fue a su casa Martín de Ayechu expresándole que "subiese luego a dichas eras pues existían en quimera los mozos de él con algunos sujetos de la villa de Aoiz". Después apareció Fermín de Abadía diciéndole que aquéllos estaban "haciendo mofa y burla que es preciso acudiese". Entonces se dirigieron hasta allí con "Ramón de Olaberri, Juan Echeverría, Martín José Monreal y Martín Ayechu" ${ }^{\text {"60 }}$. Fermín de Abadía señala que mientras estaban "bailando al son de la gaita pasaron por sus proximidades una cuadrilla de mozos de la villa de Aoiz" y mientras transitaban por el camino "volvieron a las eras quejándose que Xavier Zabalza les disparó una piedra"61. Debido a sus airadas demostraciones Nicolás Reclusa, según Ramón Olaberri, "resolvió proceder a la prisión de algunos sujetos de la cuadrilla de Aoiz" "2 aunque como indica Martín José Monreal, cuando éste fue a apresarles "andaban tirándolo y empujándolo"63. Xavier Zabalza fue señalado como uno de los culpables de haberles tirado una piedra a los vecinos de Aoiz, sin embargo se defiende señalando que éstos "iban haciendo mofa y burla a los mozos de este lugar hasta hacer el ademán de enseñar los traseros", entonces tomando un pedazo de teja "la tiró hacia el camino dando vueltas y advirtiéndolo suponiendo se practicó contra ellos vinieron al punto a las eras" ${ }^{\prime \prime 4}$.

$\mathrm{Al}$ margen de estos sucesos también se han registrado enfrentamientos armados que se ocasionaron en zonas alejadas de los núcleos de población pero que no hacen referencia a momentos festivos. En algunas ocasiones se aprecia que su estallido se debió a rencores y enemistades lastrados con el paso del tiempo, por lo que se trató de buscar la oportunidad propicia para sorprender a sus enemigos. Esto último pudo ser lo que sucedió en 1743 en la localidad de Allo, ya que allí fueron atacados mientras dormían los pastores Francisco Oyaga, Manuel de Eraso, Alejandro Ganuza y Pedro Luquín. Entre sus asaltantes se encontraron Miguel de Laspeñas, José de Laspeñas, Joaquín Caballero, Ildefonso Asín y Javier Cenigo. Según sostienen los afectados "cosas semejantes se han ejecutado diversas veces en otras ocasiones" y siempre "cogiendo a estos vecinos en el campo dormidos o

\footnotetext{
${ }^{60}$ AGN, Tribunales Reales. Procesos, núm. 193894, fol. 4.

${ }^{61}$ AGN, Tribunales Reales. Procesos, núm. 193894, fol. 5.

62 AGN, Tribunales Reales. Procesos, núm. 193894, fol. 6.

${ }^{63}$ AGN, Tribunales Reales. Procesos, núm. 193894, fol. 8.

${ }^{64}$ AGN, Tribunales Reales. Procesos, núm. 193894, fol. 9.
} 
descuidados de que han podido y pueden resultar graves inconvenientes". Hasta entonces los vecinos de Allo "acostumbran salir por las noches a pastar sus caballerías" y como consecuencia de estos acontecimientos "dudan mucho en hacerlo temerosos les suceda algún inconveniente" ${ }^{, 65}$.

Puede comprobarse, por tanto, que la elección de estos parajes no fue algo espontáneo, sino que detrás de estas acciones existía cierta premeditación, ya que con ello lo que se buscaba era sorprender a sus contrarios al asaltarles de forma sorpresiva en zonas apartadas donde no podían ser socorridos tan fácilmente. Es por ello por lo que se buscaron caminos y prados alejados de las poblaciones. No obstante, la documentación consultada para el caso navarro nos da muestra de que se trató de una práctica bastante exigua, puesto que únicamente el $6 \%$ de los altercados que se originaron en el reino de Navarra entre 1512 y 1808 aparecen registrados en estos espacios.

\section{LAS TABERNAS: ALCOHOL Y VIOLENCIA}

Por último, creo conveniente destacar el papel que desempeñaron los espacios tabernarios como generadores de enfrentamientos violentos entre los navarros de los siglos modernos. Resulta evidente que el mayor atractivo que ofrecieron estos escenarios a sus clientes fue la venta de alcohol, por lo que se convirtieron en un lugar predilecto para que surgiesen tanto dentro como fuera de ellas todo tipo de altercados. No obstante, tras los 12 sucesos que han sido testimoniados para Navarra se constata el surgimiento de dichos enfrentamientos a modo de pendencias entre grupos rivales con ocasión del consumo excesivo de bebidas alcohólicas.

Sin duda, las tabernas se convirtieron en un enclave fundamental de la sociabilidad comunitaria $^{66}$, en donde no sólo se puso de manifiesto el gusto por la diversión sino también la facilidad que tiene el género humano para la discusión ${ }^{67}$.

65 AGN, Tribunales Reales. Procesos, núm. 167400, fol. 3.

66 Véanse las referencias que aportan IGLESIAS ESTEPA, R. (2008). «Violencia física y verbal en la Galicia de finales del Antiguo Régimen». Semata, 19, p. 156; BonNET, M. R. (1994). «Le vocabulaire de la violence tel qu'il apparaît dans quelques textes non littéraires du XIVe et du XVe siècle en Provençal». VV.AA. (eds.). La violence dans le monde medieval. Centre Universitaire d'Etudes et de Recherches Médiévales d'Aix. France: Université de Provence, p. 74; Mantecon Movellan, T. A. (1997). op. cit., p. 100; MUCHEMBLED, R. (1994). op. cit., p. 77.

${ }^{67}$ Como acertadamente también lo han indicado BERNAL SERNA, L. M. (2003). op. cit., p. 410; BERCÉ, Y. M. (1990). History of peasant revolts. The social origins of rebellion in Early Modern France. London: Polity, p. 34; Muchembled, R. (1987). «Anthropologie de la violence dans la France moderne (XVe-XVIIIe siècle)». Revue de synthèse, CVIII, p. 42; CANDAU CHACóN, M. L. 
Ello puede comprobarse, por ejemplo, en la demanda que interpusieron en 1563 los jurados, concejo y vecinos de Aquerreta porque según ellos "han sucedido muertes y heridas, y escándalos en las dichas tabernas" ${ }^{68}$. Sobre los altercados que se originaban en ellas nos informa Guillén de Irure, quien sostenía que hacía unos meses "sucedió cierta riña y cuestión y de ella remaneció herido uno llamado Luis". Declaración que fue ratificada por Juan de Oroz al indicar que en las tabernas "han sucedido muchas cuestiones, riñas y alborotos" $"$. No nos debe extrañar lo más mínimo que en el interior de los espacios tabernarios se configurasen lances armados entre diferentes cuadrillas. De esta manera, una noche de 1754 en la ciudad de Estella cayó herido Francisco de Echauri. Este personaje fue a la taberna de José de Senosiain con Ildefonso Royo, en donde ya se encontraban Lucas de Esparza, Ramón de Vidarte, José de Irisarri y Sebastián de Ugarte. Parece ser que tuvieron cierta diferencia al haberse jugado varias pintas de vino que habían perdido frente a Echauri, ante lo que Ugarte le dijo que "era un borracho" ${ }^{70}$. Fue entonces cuando le sorprendieron varios sujetos al agredido, a quien según Esteban de Eraso, maestro cirujano, le provocaron "una herida en la cara ejecutada con instrumento punzante y cortante en el lado derecho, grande en su esencia, desde la ceja cogiendo todo lo carnoso con fractura en el músculo temporal, aunque dicha fractura es al principio del dicho hueso" ${ }^{, 71 .}$ Se constata, por tanto, el elevado peligro que podía ocasionar el excesivo consumo de alcohol debido a sus nocivas consecuencias, a lo que además se le debía sumar lo perjudiciales e intempestivas que resultaban las horas en que se solía llevar a cabo este tipo de prácticas.

En conclusión, pese a que en el reino de Navarra únicamente se registraron un $4 \%$ de las causas relativas a desórdenes públicos en las tabernas, queda claramente de manifiesto que se trató de un ambiente propicio para que sucedieran infinidad de enfrentamientos entre cuadrillas rivales. Aunque en este tipo de enclaves también es cierto que no podemos desligar la aparición de altercados con el consumo de alcohol, por lo que una cosa va unida a la otra.

(1993). Los delitos y las penas en el mundo eclesiástico sevillano del XVIII. Sevilla: Diputación Provincial de Sevilla, p. 126, Collins, J. B. (2006). La Bretagne Dans l'État royal. Classes sociales, États provinciaux et ordre public de l'Édit d'Únion à la révolte des Bonnets rouges. France: Presses Universitaires de Rennes, p. 92; GONTHIER, N. (1993). Délinquance, justice et société dans le Lyonnais medieval. De la fin du XIIIe siècle au début du XVIe siècle. Paris: Arguments, p. 98.

${ }^{68}$ AGN, Tribunales Reales. Procesos, núm. 66966, fol. 1.

${ }^{69}$ AGN, Tribunales Reales. Procesos, núm. 66966, fol. 3.

${ }^{70}$ AGN, Tribunales Reales. Procesos, núm. 92954, fol. 2.

${ }^{71}$ AGN, Tribunales Reales. Procesos, núm. 92954, fol. 1. 


\section{CONCLUSIONES}

El desorden público debe ser entendido como una expresión manifiesta de la violencia popular que se ejerció durante los siglos modernos. Ésta debemos concebirla como una expresión propia que se caracterizó no sólo por tratar de alcanzar unos fines determinados, sino también por poseer un lenguaje privativo y unas tácticas específicas. Sin duda, si por algo se caracterizó la conflictividad durante los siglos modernos fue porque sus manifestaciones violentas se ocasionaron, generalmente, en fechas, lugares y situaciones muy concretas. Además éstas estuvieron acompañadas de una cierta ritualización en sus comportamientos y en sus formas. Es por ello por lo que uno de los objetivos que he tratado de alcanzar a través de este trabajo ha sido llegar a mostrar si existió o no cierta lógica en la conformación de estallidos violentos. Pudiéndose comprobar que los causantes de alteraciones del orden supieron en todo momento cuáles eran los espacios más idóneos para desarrollar sus intenciones.

Unido a ello, considero que gracias al presente estudio se ha logrado indagar de forma certera en la estructura y en los aspectos formales que adoptó la conflictividad cotidiana que sacudió el reino de Navarra entre 1512 y 1808. Para ello se ha analizado, desde mi punto de vista, una de las características básicas de las distintas acciones de naturaleza colectiva, caso del reparto espacial que arrojan los conflictos que estallaron en nuestro territorio. Si bien es cierto que este artículo ha pretendido ir un poco más allá de una mera descripción, ya que ha tratado de explicar de un modo coherente los motivos de su distribución en diferentes emplazamientos.

Lo que se ha puesto de manifiesto tras analizar los distintos espacios en los que se reprodujeron de un modo más habitual todo tipo de desórdenes públicos es que la documentación procesal resulta vital para llegar a comprender la constante presencia que tuvieron los comportamientos violentos en los lugares de ocio y diversión. Tanto es así que se ha comprobado que tanto las calles, las plazas o las tabernas recogieron un número inigualable de disturbios, ya que entre las tres suman un $77 \%$ del total de los sucesos que tuvieron lugar durante la Edad Moderna. Pese a ello, es cierto que en otras zonas en donde debería de haber existido una mayor estabilidad y tranquilidad socio-comunitaria también estallaron con suma frecuencia conflictos vecinales. Ello se pone de manifiesto, por ejemplo, en los recintos religiosos, los ayuntamientos y concejos, y en las zonas apartadas de los núcleos de población. Estas tres representan el 23\% restante que falta para completar la totalidad de los casos estudiados.

En suma, todo esta situación lo que corrobora es que la agresividad fue una 
pauta de comportamiento sumamente extendida en las sociedades de la Europa occidental de aquellas centurias, pudiéndose generar diferentes tipos de alteraciones a escala local por cualquier motivo y en determinados enclaves. En total para la Navarra moderna se han terminado localizando seis, lo que no quita para que se haya confirmado la riqueza de cada uno de ellos. Erigiéndose en la práctica como espacios autónomos al registrarse determinados altercados que no se localizaban en otros lugares, aunque también es cierto que este artículo ha conseguido reflejar las coincidencias existentes entre ellos. Pese a ello, lo que se ha comprobado es que la calle se convirtió en el escenario más importante en el que se puso de manifiesto la cultura popular a lo largo del Antiguo Régimen. No obstante, de todo ello lo que puede deducirse es la complejidad que caracterizó a la violencia colectiva, asunto que considero que ha logrado ponerse de manifiesto a lo largo de estas líneas para llegar a comprender mucho mejor sus formas. 